Check for updates

Cite this: Chem. Sci., 2018, 9, 8234

๑ All publication charges for this article have been paid for by the Royal Society of Chemistry

Received 25th June 2018

Accepted 5th September 2018

DOI: $10.1039 / \mathrm{c} 8 \mathrm{sc} 02782 \mathrm{j}$

rsc.li/chemical-science

\section{Synthesis and reactivity of a $\mathrm{PC}_{\text {carbene }} \mathrm{P}$ cobalt( $(1)$ complex: the missing link in the cobalt PXP pincer series $(X=B, C, N) \uparrow$}

\author{
Simon Sung, (D) ${ }^{a}$ Qingyang Wang, ${ }^{a}$ Tobias Krämer $\mathbb{D}^{b}$ and Rowan D. Young (D) *a
}

We report the first example of a cobalt $P C_{\text {carbene }} \mathrm{P}$ pincer complex (1) featuring a central alkylidene carbon donor accessed through the dehydration of an alcoholic POP proligand. Complex 1 shares bonding similarities with cobalt PBP and PNP pincer complexes where the donor atom engages in $\pi$-bonding with the cobalt centre, and thus completes the PXP $(X=B, C, N)$ pincer ligand series for cobalt (for $X$ donors that partake in $M-L \pi$-bonding). As compared to PBP and PNP pincer complexes, which are known to be good hydride and proton acceptors (respectively), complex 1 is found to be an effective hydrogen atom acceptor. Complex 1 partakes in cooperative ligand reactivity, engaging in several small molecule activations with styrene, bromine, carbon disulphide, phenyl acetylene, acetonitrile, hydrogen, benzaldehyde and water (through microreversibility). The mechanism for the formation of complex 1 is studied through the isolation and computational analysis of key intermediates. The formation of 1 is found to avoid $\mathrm{C}-\mathrm{H}$ activation of the proligand, and instead proceeds through a combination of $\mathrm{O}-\mathrm{H}$ activation, hydrogen atom transfer, $\beta$-hydride elimination and hydrogen activation processes.

\section{Introduction}

Pincer ligands (i.e. tridentate meridional ligands) form a fundamental scaffold upon which many transition metal complexes are based. Pincer ligands have been pivotal in the development of $\mathrm{C}-\mathrm{C}, \mathrm{C}-\mathrm{H}, \mathrm{C}-\mathrm{O}, \mathrm{N}-\mathrm{H}$ and $\mathrm{O}-\mathrm{H}$ activation chemistries (inter alia), and are increasingly being used as supports in transition metal catalysis. ${ }^{1}$ As chemists place increasing importance on base metal catalysis in developing sustainable, cheap and non-toxic catalysts, PXP (X $=\mathrm{B}$ or $\mathrm{N})$ pincer systems that are complicit in metal-ligand cooperativity have emerged as versatile supporting ligands for a wide array of chemical transformations.

In particular, recent developments of cobalt PBP and PNP pincer systems have allowed advances in olefin hydrogenation, ${ }^{2}$ ester hydrogenation, ${ }^{3}$ ketone alkylation, ${ }^{4}$ carbon dioxide hydrogenation, ${ }^{5}$ transfer hydrogenation of alkynes, olefins and nitriles, ${ }^{6}$ amine alkylation, ${ }^{7}$ dinitrogen reduction, ${ }^{8}$ and $\mathrm{C}-\mathrm{H}$ borylation $^{9}$ (inter alia). The unique activity of these systems is in large part due to $\pi$-interaction between the cobalt metal centre and the N/B donor. This interaction is possible through the $\mathrm{sp}^{2}$

${ }^{a}$ Department of Chemistry, National University of Singapore, 3 Science Drive 3, Singapore 117543. E-mail: rowan.young@nus.edu.sg

${ }^{b}$ Department of Chemistry, Maynooth University, Maynooth, Ireland

$\dagger$ Electronic supplementary information (ESI) available. CCDC 1848387-1848397. For ESI and crystallographic data in CIF or other electronic format see DOI: $10.1039 / \mathrm{c} 8 \mathrm{sc} 02782 \mathrm{j}$ hybridisation of the N/B donor atoms observed in molecular structures of cobalt PNP and PBP complexes.

Although there are known examples of $\mathrm{sp}^{2}$ hybridised carbon PCP systems for cobalt, up to now they are restricted to carbon donors housed in aryl systems. ${ }^{10}$ Such complexes are poor analogues of PBP and PNP systems, in that they interact predominantly with the cobalt centre through a C-Co $\sigma$-coordination. In contrast, PBP and PNP systems are able to act as $\pi$ acids and $\pi$-bases respectively, somewhat akin to Fischer and Schrock carbene analogues (Fig. 1). As such, PCP alkylidene $\left(\mathrm{PC}_{\text {carbene }} \mathrm{P}\right)$ systems, with a central carbene donor, are perhaps the most suitable description for an intermediary between PBP and PNP pincer systems, and they would prove valuable ligands in exploring the reactivity spectrum of PXP ligands on cobalt. ${ }^{11}$ Yet examples of $\mathrm{PC}_{\text {carbene }} \mathrm{P}$ ligands for first row transition metals

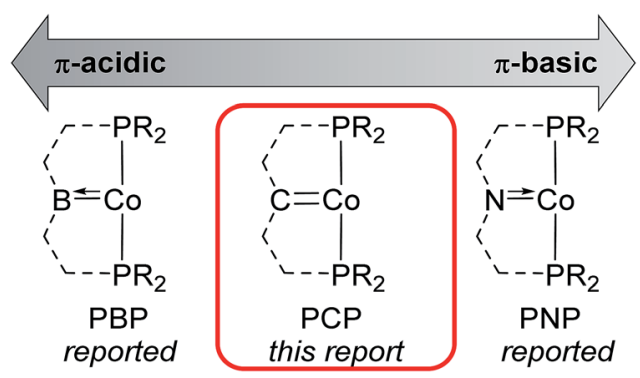

Fig. 1 Cobalt PXP pincer ligand architectures involving Co-X $\pi$ interaction based on boron, carbon and nitrogen central $X$ donors. PBP and PNP systems are widely reported (see ref. 2-9 for examples). 
are largely unknown, except for a recent report concerning $\mathrm{PC}_{\text {carbene }} \mathrm{P}$ nickel complexes by Piers. ${ }^{\mathbf{1 2}}$

The near absence of first row $\mathrm{PC}_{\text {carbene }} \mathrm{P}$ complexes can primarily be attributed to the restricted synthetic methodology available to access such systems. Early $\mathrm{PC}_{\text {carbene }} \mathrm{P}$ systems, based on aliphatic backbones, were reported by Shaw and then Gusev. ${ }^{13}$ Ozerov, and later Piers, introduced $\beta$-hydride elimination resistant systems. ${ }^{14}$ All of these systems are reliant upon double $\mathrm{C}-\mathrm{H}$ activation, and are thus restricted to metals capable of facile $\mathrm{C}-\mathrm{H}$ activation (i.e. noble metals). Indeed, prior reports of the installation of methylene bridged bisphosphino ligands on electron rich cobalt centres failed to provide evidence of double $\mathrm{C}-\mathrm{H}$ activation. ${ }^{15}$ Piers, and later Iluc, developed double dehydrohalogenation methodologies for group 10 metal dihalides, which proceeded via electrophilic $\mathrm{C}-\mathrm{H}$ activation then hydrohalide abstraction with a suitably strong base. ${ }^{\mathbf{1 2 a}, \mathbf{1 6}}$ Thus, over the previous 40 years, only $\mathrm{Os}, \mathrm{Ru}, \mathrm{Ir}, \mathrm{Rh}, \mathrm{Pd}$ and $\mathrm{Ni}$ $\mathrm{PC}_{\text {carbene }} \mathrm{P}$ systems have been reported.

Metals supported by $\mathrm{PC}_{\text {carbene }} \mathrm{P}$ ligands have shown the ability to partake in a variety of ligand cooperativity reactions, ${ }^{17}$ including 1,2-bond addition, ${ }^{\mathbf{1 2 a}, \mathbf{1 3 a}, \mathbf{1 4 b}}[2+2]$ cycloaddition, ${ }^{\mathbf{1 8}}$ Frustrated Lewis pair type reactivity, ${ }^{16 \boldsymbol{b}}$ radical reactivity, ${ }^{\mathbf{1 6 c}, \boldsymbol{d}}$ redox reactivity, ${ }^{\mathbf{1 4 c , 1 6 e}}$ chalcogen abstraction ${ }^{\mathbf{1 4 f , 1 6 f}}$ and ligand directed bond-activation. ${ }^{19}$ Thus, a variety of bond activations, including $\mathrm{H}-\mathrm{H}, \mathrm{C}-\mathrm{H}, \mathrm{N}-\mathrm{H}, \mathrm{O}-\mathrm{H}$ and $\mathrm{N}-\mathrm{O}$ bonds (inter alia), have demonstrated the potential of these systems for future catalytic purposes. However, routine access to these ligands continues to limit progress in the field, especially in the area of $\mathrm{PC}_{\text {carbene }} \mathrm{P}$ base metal complex reactivity.

Recently while exploring the mechanism of transfer hydrogenation mediated by acidic rhodium hydrides, ${ }^{20}$ we realized that facile access to $\mathrm{PC}_{\text {carbene }} \mathrm{P}$ systems could be achieved directly via dehydration of PCP $\alpha$-hydroxyalkyl ligands. ${ }^{18,19}$ As such ligands can be generated by carbonyl insertion into metal hydrides, $\mathrm{C}-\mathrm{H}$ activation of the proligand can be avoided completely.

Herein, we report the extension of this method to cobalt $\mathrm{PC}_{\text {carbene }} \mathrm{P}$ systems. The mechanism of formation is interrogated to distinguish between possible $\mathrm{C}-\mathrm{H}$ and $\mathrm{O}-\mathrm{H}$ activation pathways, and the $\mathrm{PC}_{\text {carbene }} \mathrm{P}$ system is compared to reported PBP and PNP cobalt systems to evaluate the electronic properties of the $\mathrm{PC}_{\text {carbene }} \mathrm{P}$ ligand on cobalt. The central alkylidene donor of the $\mathrm{PC}_{\text {carbene }} \mathrm{P}$ ligand enables a wide array of reactivity with cobalt including $\mathrm{C}-\mathrm{H}$ bond activation, $\mathrm{C}-\mathrm{C}$ bond activation, $\mathrm{C}-\mathrm{C}$ bond formation, $\mathrm{C}-\mathrm{N}$ bond activation, $\mathrm{H}-\mathrm{H}$ bond activation and hydrogen atom transfer.

\section{Results and discussion}

Cobalt(I) $\mathrm{PC}_{\text {carbene }} \mathrm{P}$ complex 1 was generated directly from the reaction of alcoholic proligand $\mathbf{A}$ with $\left[\mathrm{Co}\left(\mathrm{PMe}_{3}\right)_{4}\right]\left[\mathrm{BAr}_{4}^{\mathrm{F}}\right]\left\{\mathrm{Ar}^{\mathrm{F}}=\right.$ 3,5- $\left.\left(\mathrm{CF}_{3}\right)_{2} \mathrm{C}_{6} \mathrm{H}_{3}\right\}$ in a one-step process (Scheme 1). Previously, we accessed a related cationic rhodium $\mathrm{PC}_{\text {carbene }} \mathrm{P}$ system via a twostep synthesis involving $\mathrm{C}-\mathrm{H}$ activation of $\mathbf{A}$ by $\left[\mathrm{RhCl}\left(\mathrm{PPh}_{3}\right)\right.$ (COD)], then salt metathesis with $\mathrm{Na}\left[\mathrm{BAr}_{4}^{\mathrm{F}}\right]$ that induced ligand dehydration. ${ }^{18}$

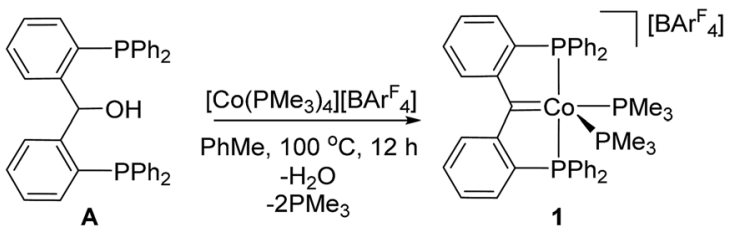

Scheme 1 Synthesis of the cationic $\mathrm{PC}_{\text {carbene }} \mathrm{P}$ cobalt complex 1 . Compound 1 was obtained in $47 \%$ isolated yield.

In contrast to the reaction of $\mathbf{A}$ with rhodium as described above, formation of 1 required overnight heating. Upon cooling of the reaction solution, compound 1 crystallizes in $47 \%$ yield. A molecular structure of $\mathbf{1}$ obtained from an X-ray diffraction study of a crystal sourced directly from the reaction solution revealed the alkylidene linkage within the $\mathrm{PC}_{\text {carbene }} \mathrm{P}$ ligand (Fig. 2). The Co1-C1 distance of 1.892(3) A in 1 falls in the range of previously reported cobalt Fischer carbenes, supporting a $\mathrm{Co}(\mathrm{I})$ assignment, ${ }^{21}$ and comparison of $\mathrm{M}=\mathrm{C}$ distances between 1 and Piers' $\mathrm{Ni}(\mathrm{II}) \mathrm{PC}_{\text {carbene }} \mathrm{P}$ examples are within experimental error $(6 \sigma) .{ }^{12 a}$ The angle sum of atoms subtending the carbene donor, $\mathrm{C} 1$, is $359.7(3)^{\circ}$, indicative of an $\mathrm{sp}^{2}$ carbon hybridisation. A ${ }^{13} \mathrm{C}$ NMR signal was observed at $216.6 \mathrm{ppm}$ $\left(\mathrm{ddt},{ }^{2} J_{\mathrm{PC}}=33.5(\mathrm{~d}), 33.5(\mathrm{~d}), 18.2(\mathrm{t}) \mathrm{Hz}\right)$, much further downfield than Piers' $\mathrm{Ni}(\mathrm{II}) \mathrm{PC}_{\text {carbene }} \mathrm{P}$ complex $\left(\delta_{\mathrm{C}}\right.$ 181.8). The majority of non-heteroatomic stabilised cobalt alkylidene complexes reported to date are paramagnetic, ${ }^{22}$ precluding suitable comparison of the carbenic ${ }^{13} \mathrm{C}$ NMR resonance within this class of compounds, however, unsurprisingly the ${ }^{13} \mathrm{C}$ NMR resonance of $\mathbf{1}$ is upfield of reported oxygen and nitrogen stabilised Fischer carbene examples. ${ }^{\mathbf{2 1 a}, \boldsymbol{c}}$

The coordination sphere of cobalt is completed by two $\mathrm{PMe}_{3}$ ligands, arranging themselves in axial and equatorial positions within the distorted square pyramidal geometry of the cobalt centre. The $\mathrm{PMe}_{3}$ ligand in the pseudo-trans position to $\mathrm{C} 1$ is elongated relative to the $\mathrm{PMe}_{3}$ in the axial position, with respective bond lengths of 2.254(1) A (Co1-P3) and 2.224(1) (Co1-P4).

In $\mathrm{CD}_{2} \mathrm{Cl}_{2}$ solution, two broad signals of equal integration are observed in the ${ }^{31} \mathrm{P}$ NMR spectrum of 1 at 52.8 and $2.2 \mathrm{ppm}$,

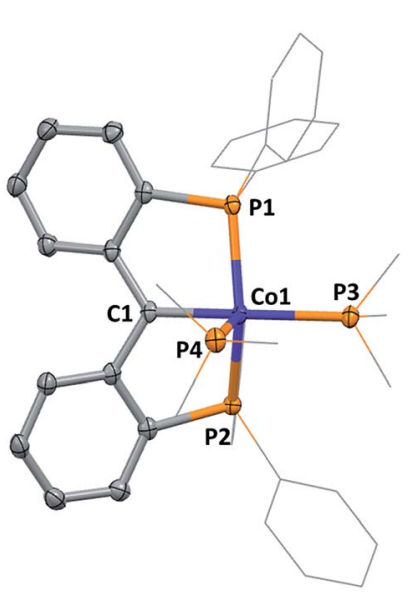

Fig. 2 Molecular structure of 1 . Hydrogen atoms and anion omitted, thermal ellipsoids shown at $50 \%$. 
corresponding to the $\mathrm{PC}_{\text {carbene }} \mathrm{P}$ and $\mathrm{PMe}_{3}$ phosphorus ligands respectively. Cooling a sample of 1 in $\mathrm{CD}_{2} \mathrm{Cl}_{2}$ to $198 \mathrm{~K}$ resolves the $\mathrm{PMe}_{3}$ phosphorus signals into a triplet of doublets at $-9.2 \mathrm{ppm}\left({ }^{2} J_{\mathrm{pp}}=58.5(\mathrm{t}), 22.3(\mathrm{~d}) \mathrm{Hz}\right)$ and a triplet of doublets at $15.0 \mathrm{ppm}\left({ }^{2} J_{\mathrm{PP}}=31.0(\mathrm{t}), 25.6(\mathrm{~d}) \mathrm{Hz}\right)$. The $\mathrm{PC}_{\text {carbene }} \mathrm{P}$ ligand's phosphorus signal at $198 \mathrm{~K}$ is observed as a doublet of doublets at $54.7 \mathrm{ppm}\left({ }^{2} J_{\mathrm{PP}}=58.5,31.0 \mathrm{~Hz}\right)$.

Direct comparison of 1 to the isoelectronic PNP cobalt(I) complex, $\left[\mathrm{PNPCo}\left(\mathrm{PMe}_{3}\right)_{2}\right]\left(\mathrm{PNP}=\kappa^{3}-\mathrm{P}^{\prime}, \mathrm{N}, \mathrm{P}^{\prime \prime}-\left\{\left(\mathrm{Ph}_{2} \mathrm{PC}_{6} \mathrm{H}_{4}\right)_{2} N\right\}\right)$ reported by Sun (Fig. 3), demonstrates the structural similarities between PNP and $\mathrm{PC}_{\text {carbene }} \mathrm{P}$ ligands. ${ }^{23}$ For example, Sun's PNP complex displays an angle sum of $359.7(5)^{\circ}$ around the nitrogen donor atom and a Co-N bond length of 2.026(3) $\AA$. The carbene ligand in $\mathbf{1}$ also displays an enhanced trans influence compared to its PNP congener with a longer $\mathrm{Co}-\mathrm{PMe}_{3}$ bond length trans to the pincer central donor of 2.254(1) $\AA$ \{cf. 2.163(1) $\AA$.

The PBP congener of $\mathbf{1}$ is not reported, thus cannot be directly compared, however, it is noted that isoelectronic iridium $\mathrm{PBP}$ and $\mathrm{PC}_{\text {carbene }} \mathrm{P}$ complexes $\left\{\right.$ viz. $\left[\left(\kappa^{3}-\mathrm{P}^{\prime}, \mathrm{B}, \mathrm{P}^{\prime \prime}-\left\{\left(\mathrm{iPr}_{2^{-}}\right.\right.\right.\right.$ $\left.\left.\left.\left.P \mathrm{C}_{6} \mathrm{H}_{4}\right)_{2} B\right\}\right) \operatorname{Ir}(\mathrm{CO})_{2}\right]$ and $\left.\left[\left(\kappa^{3}-\mathrm{P}^{\prime},=\mathrm{C}, \mathrm{P}^{\prime \prime}-\left\{\left(\mathrm{iPr}_{2} P_{6} \mathrm{C}_{4}\right)_{2} C\right\}\right) \operatorname{Ir}(\mathrm{CO})_{2}\right]^{+}\right\}^{14 e, 24}$ have been reported by Ozerov (PBP) and Piers $\left(\mathrm{PC}_{\text {carbene }} \mathrm{P}\right)$, and that the trans influence of the $\mathrm{PC}_{\text {carbene }} \mathrm{P}$ ligand is greater than that of the PBP ligand in these systems. Comparison of the Co1-C1 bond length in 1 to a Co-B distance of 1.946(1) $\AA$ in Peters' PBP cobalt(I) complex $\left.\left[\mathrm{PBPCo}\left(\mathrm{N}_{2}\right)\right]^{2 a} \quad \mathrm{PBP}=\kappa^{3}-P, B, P^{\prime}-B\left(\mathrm{NCH}_{2} P^{t} \mathrm{Bu}_{2}\right)_{2} \mathrm{C}_{6} \mathrm{H}_{4}\right\}$, indicates enhanced higher bonding in the carbon-cobalt bond of the $\mathrm{PC}_{\text {carbene }} \mathrm{P}$ ligand on $\operatorname{cobalt}(\mathrm{I})$ as compared to boron and nitrogen interactions in similar PBP and PNP ligand scaffolds.

Calculated iso-surfaces for the HOMO-1 and LUMO-1 orbitals of 1 show the LUMO to be predominantly located on the carbene ligand (Fig. 4). This observation is in agreement with the Fischer type alkylidene reactivity observed for compound 1 with a range of nucleophiles (vide infra).

Addition of one equivalent of $\mathrm{B}\left(\mathrm{C}_{6} \mathrm{~F}_{5}\right)_{3}$ to a solution of 1 results in sequestration of one of the $\mathrm{PMe}_{3}$ ligands as $\left[\mathrm{Me}_{3} \mathrm{P}-\right.$ $\left.\mathrm{B}\left(\mathrm{C}_{6} \mathrm{~F}_{3}\right)_{3}\right]^{25}$ and formation of complex 2 (Fig. 5). The use of less acidic $\mathrm{BPh}_{3}$ was also found to generate 2 , although with a much lower conversion than $\mathrm{B}\left(\mathrm{C}_{6} \mathrm{~F}_{5}\right)_{3}$. The stability of complex 2 was found to be solvent dependent, with the coordinating solvent, MeCN, stabilizing 2 in solution as [2.MeCN]. Indeed, the dissolution of $\mathbf{1}$ in MeCN generates an equilibrium between 1 and $[\mathbf{2} \cdot \mathrm{MeCN}]$. In non-coordinating solvents, $\mathbf{2}$ was found to decompose over time, excluding the possibility of obtaining a molecular structure of the four-coordinate $\mathrm{PC}_{\text {carbene }} \mathrm{P}$ cobalt complex, however, the identity of 2 was confirmed by the

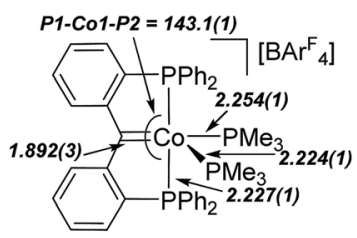

1

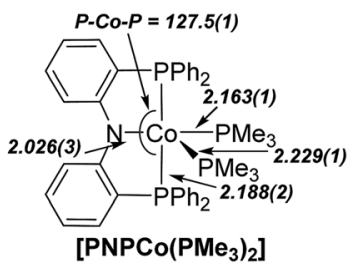

[PNPCo $\left(\mathrm{PMe}_{3}\right)_{2}$ ]
Fig. 3 Comparison of the molecular metrics of the congeners 1 (left) and $\left[\left(\kappa^{3}-P^{\prime}, N, P^{\prime \prime}-\left\{\left(P_{2} P_{6} C_{6} H_{4}\right)_{2} N\right\}\right) C o\left(P M e_{3}\right)_{2}\right]^{22}$ (right). Selected bond distances $(\AA)$ and angles $\left(^{\circ}\right)$ displayed.

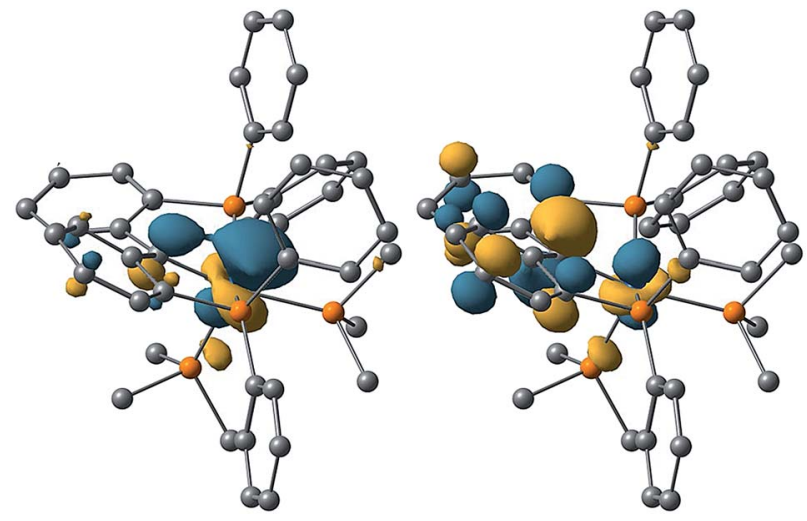

Fig. 4 Calculated structure of 1 showing HOMO (left) and LUMO (right) iso-surface (0.05 a.u. cutoff).

addition of an equivalent of $\mathrm{PMe}_{3}$, which reformed 1 quantitatively.

\section{Small molecule activation}

The reactivity of $\mathbf{1}$ and $\mathbf{2}$ was explored with a number of reagents and is summarized in Fig. 5. As stated above, cobalt(I) $\mathrm{PC}_{\text {carbene }} \mathrm{P}$ complexes may be described within the cobalt(I) PBP-PNP spectrum (Fig. 1). It is noted that cobalt(I) PBP complexes have been shown to be good hydride acceptors, and cobalt(I) PNP complexes have been utilized as proton acceptors. ${ }^{2 a, 26}$ Considering this, we tested the reactivity of $\mathbf{1}$ and $\mathbf{2}$ with various hydrogen sources.

When 1 is treated with 1 atm of $\mathrm{H}_{2}$ in $\mathrm{PhF}$, reduction of the carbene anchor point occurs, presumably to generate $\left[\mathrm{Co}\left\{\kappa^{2}\right.\right.$ $\left.\left.\mathrm{P}, \mathrm{P}^{\prime}-\left(\mathrm{Ph}_{2} \mathrm{PC}_{6} \mathrm{H}_{4}\right)_{2} \mathrm{CH}_{2}\right\}\left(\mathrm{PMe}_{3}\right)_{2}\right]$, which is unstable under these conditions and results in the observation of liberated bisphosphine, $\left(\mathrm{Ph}_{2} \mathrm{PC}_{6} \mathrm{H}_{4}\right)_{2} \mathrm{CH}_{2}$, (as confirmed by ${ }^{1} \mathrm{H},{ }^{31} \mathrm{P},{ }^{13} \mathrm{C} \mathrm{NMR}$ spectroscopy and ESI-MS). ${ }^{27}$ When identical reaction conditions were applied using MeCN solvent \{i.e. with in situ generated $[\mathbf{2} \cdot \mathrm{MeCN}]\}$, apart from the reduced pincer ligand, a mass fragment corresponding to MeCN being incorporated into the reduced ligand was observed in the ESI-MS mass spectrum of the crude reaction mixture. Addition of hydrogen to $\mathbf{1}$ or $[2 \cdot \mathrm{MeCN}]$ in MeCN in a more controlled manner, via the use of $\mathrm{NaH}$, resulted in the generation of 3 in $52 \%$ yield, featuring a coordinated enamine motif (Fig. 5). In non-coordinating solvent (e.g. $\mathrm{PhF}$ ), 1 failed to react with $\mathrm{NaH}$, even after prolonged heating.

Cobalt NNP and CCC pincer complexes have recently been shown to be efficient catalysts towards nitrile reduction. The isolation of 3, may represent the interception of an intermediate in this process arising from 1,2-insertion of $\mathrm{MeCN}$ into a $\mathrm{Co}-\mathrm{H}$ bond, and may shed light onto the mechanism of reported cobalt pincer complex catalysed nitrile reductions. ${ }^{28}$

When 1 was treated with an equivalent of $\left[\mathrm{H}\left(\mathrm{OEt}_{2}\right)_{2}\right]\left[\mathrm{BAr}_{4}^{\mathrm{F}}\right]$ in $\mathrm{PhF},\left[\mathrm{HPMe}_{3}\right]\left[\mathrm{BAr}_{4}^{\mathrm{F}}\right]$ and 2 were generated. In contrast to reaction with $\mathrm{B}\left(\mathrm{C}_{6} \mathrm{~F}_{5}\right)_{3}$ (vide supra), this reaction only proceeded to $22 \%$ conversion. Although 1 failed to incorporate proton or hydride sources directly, it was found to act as a hydrogen atom 


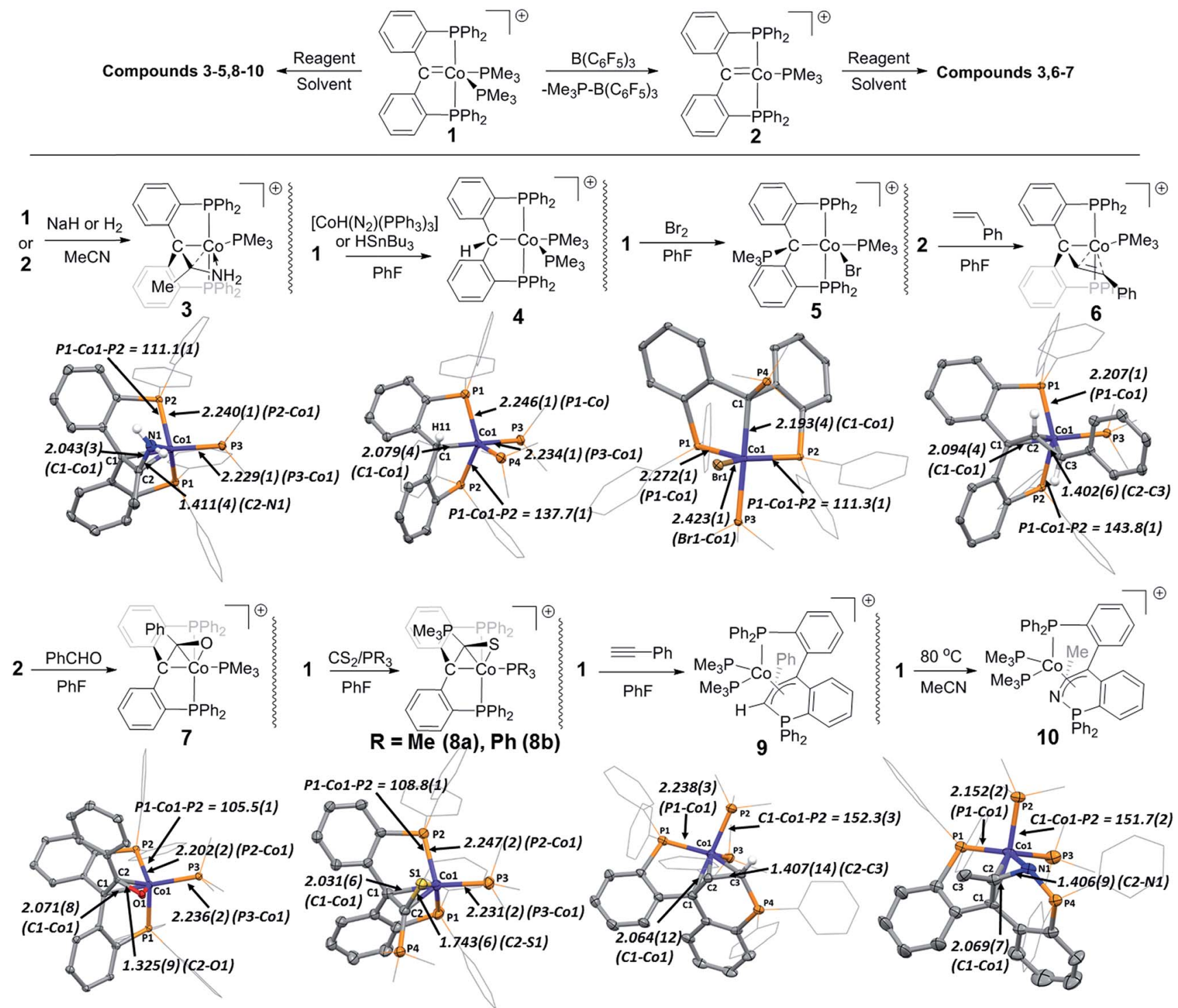

Fig. 5 Products from reactivity of 1 and 2 with various small molecules. Phenyl and methyl hydrogen atoms, and [BAr $\left.{ }_{4}^{\mathrm{F}}\right]$ anions omitted for simplification. Thermal ellipsoids shown at $50 \%$, selected bond distances $(\AA \AA)$ and angles $\left({ }^{\circ}\right)$ displayed.

acceptor in hydrogen atom transfer (HAT) reactions. For example, reaction of $\left[\mathrm{CoH}\left(\mathrm{N}_{2}\right)\left(\mathrm{PPh}_{3}\right)_{3}\right]$ or $\mathrm{HSnBu}_{3}$ with $1 \mathrm{in} \mathrm{PhF}$ resulted in complete consumption of $\mathbf{1}$ and generation of $\mathbf{4}$, as determined by ESI-MS and EPR spectroscopy. Compound 4 features a $\mathrm{PC}_{\mathrm{sp} 3} \mathrm{P}$ pincer ligand where the carbene linkage present in $\mathbf{1}$ has been transformed into an alkyl donor. Although the incorporated hydrogen was spectrometrically and crystallographically observed (i.e. located in a Fourier difference map), the $\mathrm{sp}^{3}$ nature of the carbon linkage is evident from the angle sum of the non-hydrogen atoms sub-tending the carbon donor (C1) \{angle $\Sigma=333.4(4)^{\circ}$ \}, deviating greatly from $\mathrm{sp}^{2}$ geometry. The ability of $\mathbf{1}$ to act as a potent hydrogen atom acceptor is in sharp contrast to reactivity of rhodium and iridium $\mathrm{PC}_{\text {carbene }} \mathrm{P}$ complexes, and is likely a result of the stability of cobalt(II).

In a related reaction, $\mathbf{1}$ was able to homolytically cleave elemental bromine to generate $\mathbf{5}$, featuring a cobalt(II) centre. In this instance, the bromine atom is transferred to the cobalt centre ( $c f$. the alkylidene carbon site) and a $\mathrm{PMe}_{3}$ ligand migrates to the alkylidene carbon position to again generate a $\mathrm{PC}_{\mathrm{sp} 3} \mathrm{P}$ type ligand. A mixture of compounds $\mathbf{4}$ and $\mathbf{5}$ could be generated through the reaction of hydrogen bromide with $\mathbf{1}$ (as indicated by ESI-MS), however, no reaction between $\mathbf{1}$ and hydrogen chloride was observed. Hydrogen bromide is known to generate hydrogen and bromine radicals (through homolytic bond cleavage), and the contrast between hydrogen chloride and hydrogen bromide reactivities supports the formation of $\mathbf{4}$ and 5 via one-electron oxidative processes.

Although complex 2 was found to be stable in coordinating solvents, its enhanced reactivity ( $c f$. compound 1) in noncoordinating solvents was revealed in the presence of small donor molecules. For example, generation of 2 (by addition of $\mathrm{B}\left(\mathrm{C}_{6} \mathrm{~F}_{5}\right)_{3}$ to 1$)$ in the presence of styrene led to the formation of complex 6 in PhF. No reaction between 1 and styrene was observed in the absence of added Lewis acid. Periodically 
obtained ESI-MS spectrometric data from the reaction mixture suggest that $\beta$-hydride elimination of an initial intermediate metallabutacycle generates a $\mathrm{Co}(\mathrm{III})$ allyl hydride, which then slowly loses hydrogen to generate 6. Olefin metathesis with cobalt alkylidenes is rare, but reported for fluorinated carbene groups. ${ }^{29}$ Indeed, isolated perfluorometallabutacycles (arising from $[2+2]$ cycloaddition) have been postulated to form intermediate cobalt allyl complexes upon $\beta$-fluoride activation. ${ }^{29 a}$

Similarly, although 1 underwent no reaction with benzaldehyde, reaction of 2 ggenerated in situ from 1 and $B\left(\mathrm{C}_{6} \mathrm{~F}_{5}\right)_{3}$ \} with benzaldehyde led to the formation of 7 . Compound 7 is another example of the ability of the $\mathrm{PC}_{\text {carbene }} \mathrm{P}$ ligand to enhance the $\mathrm{C}-\mathrm{H}$ activating capability of cobalt. In the formation of $7, \mathrm{C}-\mathrm{H}$ activation likely proceeds via $\beta$-hydride elimination after the formation of an oxabutacycle (in a similar manner to the formation of 6), rather than direct concerted $\mathrm{C}-\mathrm{H}$ cleavage of benzaldehyde, as is common for noble metals. The formation of metallaoxacyclobutanes is an important step in epoxide carbonylations and carboxylations, epoxide isomerisations, epoxide reductive couplings, and olefin epoxidation (inter alia). ${ }^{30}$ Compound 7 features a coordinated $\eta^{3}-\mathrm{C}, \mathrm{C}^{\prime}, \mathrm{O}-\mathrm{enolato}$ motif, arising from incorporation of benzoyl into the pincer ligand. The $\mathrm{C} 2-\mathrm{O} 1$ bond distance of 1.325(9) $\AA$, and $\mathrm{C} 1-\mathrm{C} 2$ bond distance of 1.455(10) A suggest that there is some multiple bond character in both the $\mathrm{C}-\mathrm{O}$ and $\mathrm{C}-\mathrm{C}$ bonds of the enolate ligand.

Compound 1 was found to activate a $\mathrm{C}=\mathrm{S}$ bond in carbon disulfide in $\mathrm{PhF}$ to generate 8a, with an equivalent of concomitant $\mathrm{SPMe}_{3}$ formed during the reaction. Although no other products were identified, presumably the sacrificial $\mathrm{PMe}_{3}$ (forming $\mathrm{SPMe}_{3}$ ) originated from compound 1. Thus, this reaction was optimized through the addition of an extra equivalent of $\mathrm{PMe}_{3}$, resulting in an isolated yield of $91 \%$. Interestingly, the addition of an equivalent of $\mathrm{PPh}_{3}$ as a sacrificial phosphine (in place of $\mathrm{PMe}_{3}$ ) led to compound $\mathbf{8 b}$, where $\mathrm{PPh}_{3}$ ligates the cobalt centre, and $\mathrm{SPMe}_{3}$ is again generated as a reaction by-product. In contrast to similar reactivity reported for rhodium $\mathrm{PC}_{\text {carbene }} \mathrm{P}$ complexes, where (thio)carbonyl attack of the $\mathrm{PC}_{\text {carbene }} \mathrm{P}$ alkylidene forms a central $\eta^{2}$-(thio)ketene, ${ }^{14 e, 18}$ compound 7 features a coordinated thioenolate that has presumably been generated by the attack of an $\eta^{2}$-thioketene by an auxiliary $\mathrm{PMe}_{3}$ ligand. Generation of the thioenolate ligand demonstrates greater bond activation by cobalt as compared to our previously reported activation of $\mathrm{CS}_{2}$ with a $\mathrm{PC}_{\text {carbene }} \mathrm{P}$ rhodium complex, with respective $\mathrm{C}-\mathrm{S}$ bond lengths of 1.743(6) $\AA$ and 1.582(4) $\AA$ in the cobalt thioenolate and rhodium thioketene complexes. Thiocarbonyl chemistry has been explored with cobalt, but is difficult to access directly from $\mathrm{CS}_{2}$ (c.f. Ir and $\mathrm{Rh}$ thiocarbonyl congeners). ${ }^{31}$ To the best of our knowledge $\eta^{3}$ thioenolates of cobalt are unreported.

In a similar manner to that reported for rhodium $\mathrm{PC}_{\text {carbene }} \mathrm{P}$ complexes, ${ }^{18} 1$ was found to react with phenyl acetylene at room temperature to generate $\mathbf{9}$, where the acetylene motif has combined with the carbene carbon atom to generate an allylic ligand, and one of the pincer phosphino donors has migrated to the terminal allylic carbon position. Similar phosphine migration has been reported between phosphines and metal vinyliums, ${ }^{32}$ and reports exist of phosphine nucleophilic attack on metallacyclobutadienes (formed from alkylidyne/alkyne [2 + 2] addition), ${ }^{33}$ but the combination of such reactivity is unprecedented for alkylidene moieties, apart from a previous example reported earlier by us. ${ }^{18}$ The reaction pathway for the formation of the resulting phosphino-allyl ligand present in $\mathbf{9}$ is subject to a more in-depth, ongoing investigation by our group.

In an analogous manner, the nitrile moiety of acetonitrile was found to insert across the carbon and one of the phosphorus donors of the $\mathrm{PC}_{\text {carbene }} \mathrm{P}$ ligand in $\mathbf{1}$ to generate compound 10. As stated above, $[2 \cdot \mathrm{MeCN}]$ is stable in solution at room temperature, and thus the formation of $\mathbf{1 0}$ required heating of compound 1 at $80{ }^{\circ} \mathrm{C}$ for 24 hours in acetonitrile solvent. Complex 10 displays many structural similarities to $\mathbf{9}$, and if it forms via a metallabutacyle intermediate (i.e. $[2+2]$ addition between a nitrile and alkylidene), it would mirror the $[2+2]$ addition chemistry observed in recently reported alkyne/ nitrile metathesis catalysts. ${ }^{34}$

The generation of compounds 3-10 likely proceeds via ligand cooperative homolysis, $[2+2]$ cycloaddition or migratory insertion. However, examples of isolable 1,2-addition products could not be generated with $\mathbf{1}$. This stands in stark contrast to other reported $\mathrm{PC}_{\text {carbene }} \mathrm{P}$ systems capable of ligand cooperativity that tend to activate substrates via 1,2-addition reactions (Scheme 2, top). ${ }^{\mathbf{1 2 a}, \boldsymbol{b}, \mathbf{1 4 b}, \mathbf{1 6 a}, \boldsymbol{d}, \boldsymbol{h}, \boldsymbol{i , 1 7}}$ Indeed, compound 1 was found to react with neither hydrochloric acid (vide infra) nor triethyl hydrosilane (both reagents are prone to oxidative addition), suggesting that 1,2-additions may be less favoured for this system. Despite the inability of $\mathbf{1}$ or $\mathbf{2}$ to partake in 1,2-addition reactions, challenging room temperature $\mathrm{C}-\mathrm{H}$ activation chemistry of benzaldehyde and styrene was found to proceed,
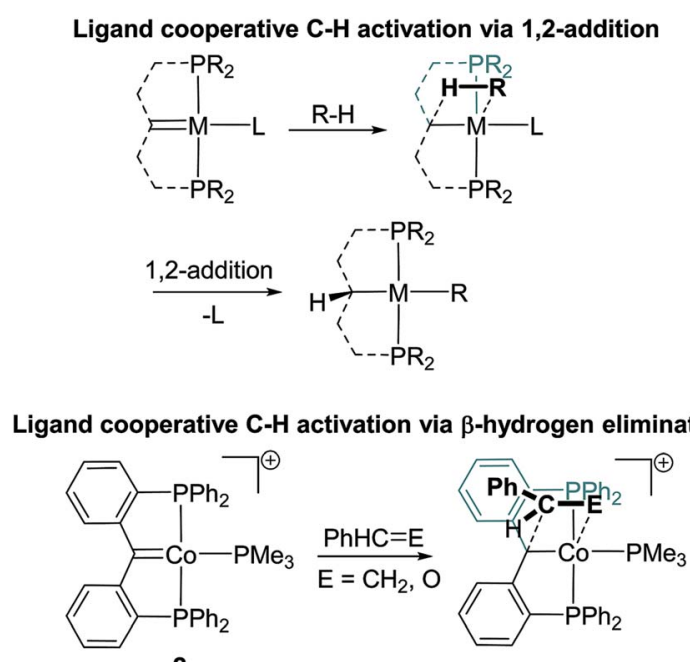

2

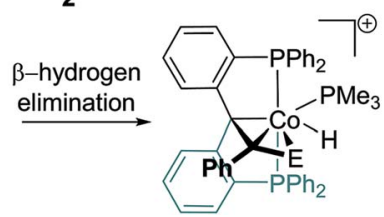

Scheme 2 (Top) Previously reported ligand cooperative $\mathrm{C}-\mathrm{H}$ activation in $\mathrm{PC}_{\text {carbene }} \mathrm{P}$ complexes via 1,2-addition. ${ }^{11 a, b, 13 b, 15,16 a, d, h, i}$ (bottom) $P C_{\text {carbene }} P$ ligand cooperative $\mathrm{C}-\mathrm{H}$ activation of styrene and benzaldehyde via $\beta$-hydrogen elimination (this report). 
via metallacycle formation and subsequent $\beta$-hydrogen elimination (Scheme 2, bottom), representing a new ligand cooperative pathway for bond activation in $\mathrm{PC}_{\text {carbene }} \mathrm{P}$ complexes.

\section{Mechanistic studies}

The reaction components and conditions chosen for the generation of 1 presumed that cobalt might undergo a single $\mathrm{C}-\mathrm{H}$ activation with proligand $\mathbf{A}$, followed by dehydration to generate 1. In reality we found the reaction pathway for the generation of $\mathbf{1}$ to be much more complex than anticipated and to completely avoid $\mathrm{C}-\mathrm{H}$ activation (Scheme 3 ). As stated above, access to 1 required overnight heating. However, it was found that at room temperature A very slowly displaced two equivalents of $\mathrm{PMe}_{3}$ in $\left[\mathrm{Co}\left(\mathrm{PMe}_{3}\right)_{4}\right]\left[\mathrm{BAr}_{4}^{\mathrm{F}}\right]$, and led to the formation of III over the period of two weeks. Compound III could also be generated in a timelier manner via one electron oxidation of the cobalt $(0)$ complex $\left[\mathrm{CoA}\left(\mathrm{PMe}_{3}\right)_{2}\right]$ using $[\mathrm{Fc}]\left[\mathrm{BAr}_{4}^{\mathrm{F}}\right]$ as an oxidant (see ESI $\dagger$ ).

Complex III was characterized via X-ray diffractrometry, which revealed a molecular geometry best described as distorted square pyramidal around the cobalt centre (Scheme 3). Compound III was found to be paramagnetic $(S=1 / 2)$, indicating a low-spin cobalt(II) centre. A Fourier difference map failed to reveal any hydrogen atoms in the coordination sphere of III, and ESI-MS spectrometric data supported the loss of a hydrogen atom and two trimethyl phosphine molecules from the constituting reaction starting components (that generate III). Cobalt phosphorus and cobalt oxygen bond distances supported the assignment of III as a cobalt(II) complex, with comparison to DFT optimized geometries of postulated $\mathrm{Co}(\mathrm{I})$ (I), Co(III) (II) and Co(II) (III) complexes concurring that III exists as a Co(II) alkoxide (see ESI†).

Complex III was confirmed as an intermediate enroute to $\mathbf{1}$ by heating isolated samples of complex III in toluene at $100{ }^{\circ} \mathrm{C}$ overnight. Under these conditions, a reduced yield of 1 was obtained (33\%).

Competing $\mathrm{O}-\mathrm{H}$ and $\mathrm{C}-\mathrm{H}$ activation pathways have been reported for similar iridium complexes resulting in formation of $\mathrm{PC}_{\text {carbene }} \mathrm{P}$ complexes. However, reactions of $\left[\mathrm{Co}\left(\mathrm{PMe}_{3}\right)_{4}\right]$ $\left[\mathrm{BAr}_{4}^{\mathrm{F}}\right]$ with oxygen protected variations of the alcohol proligand, $\mathbf{A}^{\mathrm{Me}}$ (methyl protected) and $\mathbf{A}^{\mathrm{TIPS}}$ (triisopropylsilyl protected), failed to react after heating at $100{ }^{\circ} \mathrm{C}$ for 14 hours or produce any trace of III or $\mathbf{1}$ (i.e. no $\mathrm{C}-\mathrm{H}$ activation was observed). Thus, it is likely that III is generated via $\mathrm{O}-\mathrm{H}$ activation (forming $\mathbf{~ I I}$ ) followed by loss of half an equivalent of hydrogen.

Interestingly, the (non-coordinated) keto bridged diphosphine $\mathbf{A}-\mathbf{H}_{2}$ was observed in solution during reactions that generated 1 from $\mathbf{A}$ and $\left[\mathrm{Co}\left(\mathrm{PMe}_{3}\right)_{4}\right]\left[\mathrm{BAr}_{4}^{\mathrm{F}}\right]$. Thus, it was hypothesized that III re-enters a $\mathrm{Co}(\mathrm{I}) / \mathrm{Co}(\mathrm{III})$ pathway via $\beta$ hydride elimination (producing IV) and loss of another half equivalent of $\mathrm{H}_{2}$, generating an $\eta^{2}$-keto POP cobalt(I) complex (V). Indeed, precedence for the formation of $\mathrm{PC}_{\text {carbene }} \mathrm{P}$ ligands from hydrogen and $\eta^{2}$-keto ligands has been reported in iridium systems..$^{14 f, 19}$

To test this hypothesis, complex $\mathbf{V}$ was independently generated by addition of keto proligand $\mathbf{A}-\mathbf{H}_{2}$ to $\left[\mathrm{Co}\left(\mathrm{PMe}_{3}\right)_{4}\right]$ $\left[\mathrm{BAr}_{4}^{\mathrm{F}}\right]$ in toluene at room temperature (Scheme 3 ). Compound $\mathbf{V}$
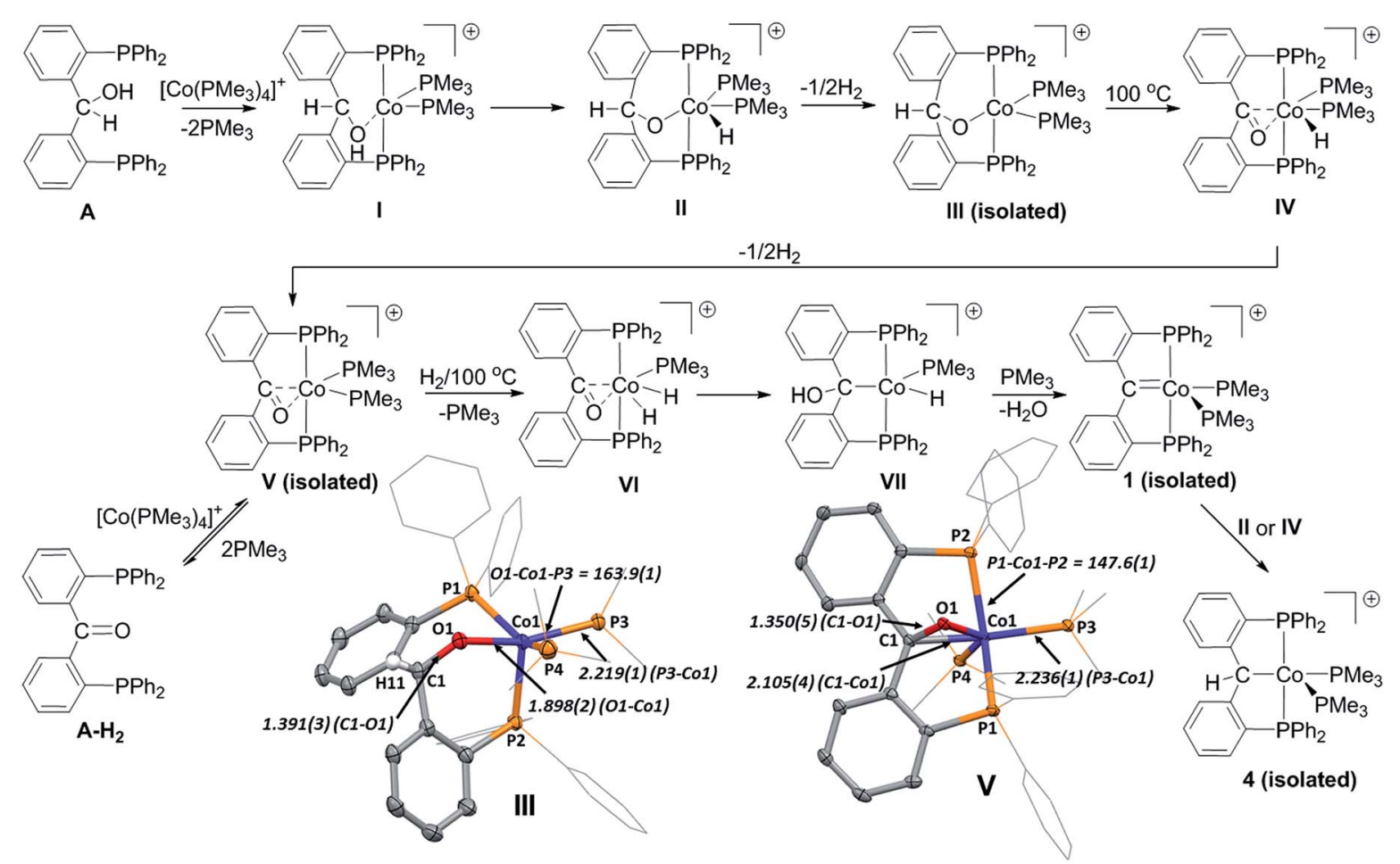

Scheme 3 Mechanistic evidence for the formation of 1. [BAr $\left.{ }_{4}^{\mathrm{F}}\right]$ anions and hydrogen atoms (except $\mathrm{H} 11$ on III) omitted for simplification. Thermal ellipsoids drawn at $50 \%$, selected bond distances $(\AA)$ and angles $\left(^{\circ}\right)$ displayed. 
exists in equilibrium with its parent reagents, thus repeated dissolution and evaporation of the mixture was required to remove liberated $\mathrm{PMe}_{3}$ and drive the reaction towards $\mathrm{V}$. A molecular structure of $\mathbf{V}$ (Scheme 3 ) confirmed the $\kappa^{3}-\mathrm{P},\left(\eta^{2}-\right.$ $\mathrm{C}, \mathrm{O}), \mathrm{P}^{\prime}$ coordination mode of the keto ligand. The ketone C1O1 distance of 1.348(5) A also suggests significant retrodonation from the cobalt centre to the $\eta^{2}$ carbonyl group $\{\mathrm{C}-\mathrm{O}=1.213(3)$ $\AA$ in proligand $\}$. Indeed, the $\mathrm{C} 1-\mathrm{O} 1$ bond distance is much greater than those reported by Moret for the related $\eta^{2}$-carbonyl nickel(0) and nickel(I) complexes, $\left[\mathrm{Ni}\left(\mathbf{A}-\mathbf{H}_{2}\right)\left(\mathrm{PPh}_{3}\right)\right]\{\mathrm{C}-\mathrm{O}=$ $1.310(2) \AA\}$ and $\left[\mathrm{NiCl}\left(\mathbf{A}-\mathbf{H}_{2}\right)\right]\{\mathrm{C}-\mathrm{O}=1.330(3) \AA 3\} .{ }^{35} \mathrm{NBO}$ analyses of $\mathbf{V}$ and Moret's nickel complexes suggest the longer $\mathrm{C}-\mathrm{O}$ distance in $\mathbf{V}$ is a result of significantly more retrodonation to a $\mathrm{C}=\mathrm{O} \pi^{*}$ orbital (see ESI $\dagger$ ).

Although 1 was not directly detected by ${ }^{31} \mathrm{P}$ NMR after addition of $\mathrm{H}_{2}$ to $\mathbf{V}$ at $100 \mathrm{C}^{\circ}$, its formation was inferred by further reactivity with $\mathrm{H}_{2}$ to generate the liberated reduced ligand $\left(\mathrm{Ph}_{2} \mathrm{PC}_{6} \mathrm{H}_{4}\right)_{2} \mathrm{CH}_{2}$ (vide supra). Additionally, compound $\mathbf{V}$ was observed to be formed and consumed (by ${ }^{31} \mathrm{P}$ NMR spectroscopy) when heating isolated samples of III in toluene at $100 \mathrm{C}^{\circ}$, which ultimately generated compound $\mathbf{1}$.

The observation of any intermediates between $\mathbf{V}$ and $\mathbf{1}$ could not be accomplished. However, based on previously reported iridium and rhodium systems, ${ }^{14 f, 18,19}$ the addition of hydrogen to V via oxidative addition (forming VI) and subsequent hydride migration to generate an $\alpha$-hydroxyalkyl complex (VII) prior to elimination of water to form 1 would constitute a valid reaction pathway.

In support of a HAT pathway mediating a $\mathrm{Co}(\mathrm{I}) / \mathrm{Co}(\mathrm{II})$ pathway, complex 4 (Fig. 5) was subsequently isolated from the supernatant of a reaction forming $\mathbf{1}$ from $\mathbf{A}$ and $\left[\mathrm{Co}\left(\mathrm{PMe}_{3}\right)_{4}\right]$ $\left[\mathrm{BAr}_{4}^{\mathrm{F}}\right]$. Given that $\mathbf{1}$ has been shown to act as a good hydrogen atom acceptor from cobalt hydrides $\left\{v i z .\left[\mathrm{CoH}\left(\mathrm{N}_{2}\right)\left(\mathrm{PPh}_{3}\right)_{3}\right]\right\}$, it is likely that in situ generated $\mathbf{1}$ may also react with cobalt hydrides II or IV to form III, accounting for the relatively moderate yields of 1 isolated after the reaction is completed (as outlined in Scheme 1).

\section{Conclusions}

We have demonstrated facile access to a $\mathrm{PC}_{\text {carbene }} \mathrm{P}$ cobalt complex (1) from an alcoholic POP proligand (A). Access to $\mathrm{PC}_{\text {carbene }} \mathrm{P}$ base metal systems is rare and synthetically difficult using traditional synthetic methods.

Complex 1 completes the triad of cobalt PXP pincer complexes featuring first-row main group $\mathrm{X}$ donors that form $\mathrm{M}-\mathrm{L} \pi$ interactions ( $\mathrm{X}=\mathrm{B}, \mathrm{C}, \mathrm{N})$. As such, complex 1 displays structural similarities to its PBP and PNP analogues. In line with this analogy, PCP acts as a good hydrogen atom acceptor, whereas PBP and PNP cobalt complexes are known to be good hydride and proton acceptors (respectively).

The enhanced reactivity of $\mathbf{1}$, induced by metal-alkylidene ligand cooperativity, enables the activation of a number of small molecules. In contrast to previously reported $\mathrm{PC}_{\text {carbene }} \mathrm{P}$ complexes, 1 does not show a tendency to partake in 1,2-addition chemistry, but is capable of homolysis, migratory insertion reactions (enabling the formation of $\mathrm{C}-\mathrm{C}$ bonds), and $[2+2]$ cycloaddition (allowing novel ligand cooperative $\mathrm{C}-\mathrm{H}$ activation). The availability of a stable cobalt(II) oxidation state may further enhance the reactivity of 1 , with compounds 4, 5, 6 and 7 all examples of compound $\mathbf{1}$ accessing a cobalt(II) oxidation state.

The formation of $\mathbf{1}$ is found to completely avoid $\mathrm{C}-\mathrm{H}$ activation, and instead proceeds via $\mathrm{O}-\mathrm{H}$ activation of alcoholic proligand A. Intermediate III suggests that a cobalt(I/II/III) reaction pathway exists meditated by molecular hydrogen. The isolation and subsequent reactivity of compound $\mathbf{V}$ implies insertion of keto ligand $\mathbf{A}-\mathbf{H}_{2}$ into a $\mathrm{Co}-\mathrm{H}$ bond to form an $\alpha$ hydroxyalkyl intermediate may represent a valid reaction pathway in forming 1.

\section{Conflicts of interest}

The authors declare no competing financial interest.

\section{Acknowledgements}

We thank the National University of Singapore and the Singapore Ministry of Education for financial support WBS R-143000-666-114, R-143-000-697-114 and R-143-000-A05-112. TK wishes to acknowledge the DJEI/DES/SFI/HEA Irish Centre for High-End Computing (ICHEC) for the provision of computational facilities and support.

\section{Notes and references}

1 (a) Organometallic Pincer Chemistry, ed. G. van Koten and D. Milstein, Topics in Organometallic Chemistry, Springer, Berlin, vol. 40, 2013; (b) E. Peris and R. H. Crabtree, Chem. Soc. Rev., 2018, 47, 1959.

2 (a) T.-P. Lin and J. C. Peters, J. Am. Chem. Soc., 2013, 135, 15310; (b) T.-P. Lin and J. C. Peters, J. Am. Chem. Soc., 2014, 136, 13672.

3 J. Yuwen, S. Chakraborty, W. W. Brennessel and W. D. Jones, ACS Catal., 2017, 7, 3735.

4 G. Zhang, J. Wu, H. Zeng, S. Zhang, Z. Yin and S. Zheng, Org. Lett., 2017, 19, 1080.

5 H. Ge, Y. Jing and X. Yang, Inorg. Chem., 2016, 55, 12179.

6 (a) S. Fu, N.-Y. Chen, X. Liu, Z. Shao, S.-P. Luo and Q. Liu, J. Am. Chem. Soc., 2016, 138, 8588; (b) G. Zhang, Z. Yina and J. Tana, $R S C A d v$. 2016, 6, 22419; (c) Z. Shao, S. Fu, M. Wei, S. Zhou and Q. Liu, Angew. Chem., Int. Ed., 2016, $\mathbf{5 5}, 14653$.

7 (a) Z. Yin, H. Zeng, J. Wu, S. Zheng and G. Zhang, ACS Catal., 2016, 6, 6546; (b) G. Zhang, Z. Yin and S. Zheng, Org. Lett., 2016, 18, 300.

8 S. Kuriyama, K. Arashiba, H. Tanaka, Y. Matsuo, K. Nakajima, K. Yoshizawa and Y. Nishibayashi, Angew. Chem., Int. Ed., 2016, 55, 14291.

9 B. A. Schaefer, G. W. Margulieux, B. L. Small and P. J. Chirik, Organometallics, 2015, 34, 1307.

10 (a) Z. Lian, G. Xua and X. Lia, Acta Crystallogr., 2010, E66, m636; (b) T. J. Hebden, A. J. S. John, D. G. Gusev, W. Kaminsky, K. I. Goldberg and D. M. Heinekey, Angew. 
Chem., Int. Ed., 2011, 50, 1873; (c) M. A. Kent, C. H. Woodall, M. F. Haddow, C. L. McMullin, P. G. Pringle and D. F. Wass, Organometallics, 2014, 33, 5686.

11 The discussion in this paper excludes cobalt pincer complexes that contain NHC-type carbene donors due to the lack of $\pi$-interaction between cobalt and the carbene in such mesomerically stabilised donors. For examples of such pincers, see: (a) B. Liu, X. Liu, C. Chen, C. Chen and W. Chen, Organometallics, 2012, 31, 282; (b) C. F. Harris, C. S. Kuehner, J. Bacsa and J. D. Soper, Angew. Chem., Int. Ed., 2018, 57, 1311; (c) C. F. Harris, M. B. Bayless, N. P. van Leest, Q. J. Bruch, B. N. Livesay, J. Bacsa, K. I. Hardcastle, M. P. Shores, B. de Bruin and J. D. Soper, Inorg. Chem., 2017, 56, 12421; (d) A. A. Danopoulos, J. A. Wright, W. B. Motherwell and S. Ellwood, Organometallics, 2004, 23, 4807; (e) A. D. Ibrahim, K. Tokmic, M. R. Brennan, D. Kim, E. M. Matson, M. J. Nilges, J. A. Bertkea and A. R. Fout, Dalton Trans., 2016, 45, 9805.

12 (a) D. V. Gutsulyak, W. E. Piers, J. Borau-Garcia and M. Parvez, J. Am. Chem. Soc., 2013, 135, 11776; (b) E. A. LaPierre, W. E. Piers, D. M. Spasyuk and W. Bi, Chem. Commun., 2016, 52, 1361; (c) A Ferraquinone complex was reported by Milstein, but was not structurally characterised, and spectroscopic evidence suggested it retained a degree of aromatic character, see: A. Dauth, U. Gellrich, Y. Diskin-Posner, Y. Ben-David and D. Milstein, J. Am. Chem. Soc., 2017, 139, 2799.

13 (a) H. D. Empsall, E. M. Hyde, R. Markham, W. McDonald, M. C. Norton, B. L. Shaw and B. Weeks, J. Chem. Soc., Chem. Commun., 1977, 589; (b) D. G. Gusev and A. J. Lough, Organometallics, 2002, 21, 2601.

14 (a) W. Weng, S. Parkin and O. V. Ozerov, Organometallics, 2006, 25, 5345; (b) R. J. Burford, W. E. Piers and M. Parvez, Organometallics, 2012, 31, 2949; (c) R. J. Burford, W. E. Piers and M. Parvez, Eur. J. Inorg. Chem., 2013, 3826; (d) J. R. Logan, W. E. Piers, J. Borau-Garcia and D. M. Spasyuk, Organometallics, 2016, 35, 1279; (e) J. D. Smith, J. R. Logan, L. E. Doyle, R. J. Burford, S. Sugawara, C. Ohnita, Y. Yamamoto, W. E. Piers, D. M. Spasyuk and J. Borau-Garcia, Dalton Trans., 2016, 45, 12669; $(f)$ L. E. Doyle, W. E. Piers and J. Borau-Garcia, $J$. Am. Chem. Soc., 2015, 137, 2187.

15 H. Zhao, H. Sun, L. Wang and X. Li, Acta Chim. Sin., 2015, 73, 1307.

16 (a) C. C. Comanescu and V. M. Iluc, Organometallics, 2014, 33, 6059; (b) P. Cui, C. C. Comanescu and V. M. Iluc, Chem. Commun., 2015, 51, 6206; (c) C. C. Comanescu, M. Vyushkova and V. M. Iluc, Chem. Sci., 2015, 6, 4570; (d) C. C. Comanescu and V. M. Iluc, Organometallics, 2015, 34, 4684; (e) P. Cui, M. R. Hoffbauer, M. Vyushkova and V. M. Iluc, Chem. Sci., 2016, 7, 4444; (f) P. Cui and V. M. Iluc, Chem. Sci., 2015, 6, 7343; $(g)$ P. E. Rothstein, C. C. Comanescu and V. M. Iluc, Chem.-Eur. J., 2017, 23, 16948; (h) C. C. Comanescu and V. M. Iluc, Chem. Commun., 2016, 52, 9048; (i) C. C. Comanescu and V. M. Iluc, Polyhedron, 2018, 143, 176.
17 K.-S. Feichtner and V. H. Gessner, Chem. Commun., 2018, 54, 6540.

18 S. Sung, T. Joachim, T. Krämer and R. D. Young, Organometallics, 2017, 36, 3117.

19 S. Sung and R. D. Young, Dalton Trans., 2017, 46, 15407.

20 S. Sung, J. K. Boon, J. J. C. Lee, N. A. Rajabi, S. A. Macgregor, T. Krämer and R. D. Young, Organometallics, 2017, 36, 1609. 21 (a) C. C. Tso and A. R. Cutler, Polyhedron, 1993, 12, 149; (b) W. D. Wulff, S. R. Gilbertson and J. P. Springer, J. Am. Chem. Soc., 1986, 108, 520; (c) A. C. Filippou and E. Herdtweck, J. Organomet. Chem., 1988, 355, 437; (d) F. Car, G. Cerveau, E. Colomer, R. J. P. Corriu, J. C. Young, L. Ricard and R. Weiss, J. Organomet. Chem., 1979, 179, 215. 22 (a) H. Lu, W. I. Dzik, X. Xu, L. Wojtas, B. de Bruin and X. P. Zhang, J. Am. Chem. Soc., 2011, 133, 8518; (b) S. L. Marquard, M. W. Bezpalko, B. M. Foxman and C. M. Thomas, J. Am. Chem. Soc., 2013, 135, 6018; (c) J. A. Bellow, S. A. Stoian, J. van Tol, A. Ozarowski, R. L. Lord and S. Groysman, J. Am. Chem. Soc., 2016, 138, 5531.

23 H. Zhao, X. Li, S. Zhang and H. Sun, Z. Anorg. Allg. Chem., 2015, 641, 2435.

24 W.-C. Shih and O. V. Ozerov, Organometallics, 2017, 36, 228. 25 G. C. Welch, T. Holtrichter-Roessmann and D. W. Stephan, Inorg. Chem., 2008, 47, 1904.

26 (a) G. Zhang and S. K. Hanson, Org. Lett., 2013, 15, 650; (b) S. S. Rozenel, R. Padilla, C. Camp and J. Arnold, Chem. Commun., 2014, 50, 2612.

27 W. Lesueur, W. Solari and C. Floriani, Inorg. Chem., 1997, 36, 3354 .

28 (a) A. Mukherjee, D. Srimani, S. Chakraborty, Y. Ben-David and D. Milstein, J. Am. Chem. Soc., 2015, 137, 8888; (b) K. Tokmic, B. J. Jackson, A. Salazar, T. J. Woods and A. R. Fout, J. Am. Chem. Soc., 2017, 139, 13554.

29 (a) D. J. Harrison, G. M. Lee, M. C. Leclerc, I. Korobkov and R. T. Baker, J. Am. Chem. Soc., 2013, 135, 18296; (b) G. M. Lee, D. J. Harrison, I. Korobkov and R. T. Baker, Chem. Commun., 2014, 50, 1128; (c) D. J. Harrison, A. L. Daniels, I. Korobkov and R. T. Baker, Organometallics, 2015, 34, 5683; (d) M. Goswami, B. de Bruin and W. I. Dzik, Chem. Commun., 2017, 53, 4382.

30 (a) C.-Y. Huang and A. G. Doyle, Chem. Rev., 2014, 114, 8153; (b) A. Dauth and J. A. Love, Chem. Rev., 2011, 111, 2010.

31 (a) H. Werner and O. Kolb, Angew. Chem., Int. Ed., 1979, 18, 865; (b) C. Bianchini, A. Meli and G. Scapacci, Organometallics, 1983, 2, 1834.

32 S. A. Fairhurst, D. L. Hughes, K. Marjani and R. L. Richards, J. Chem. Soc., Dalton Trans., 1998, 1899.

33 (a) L. L. Padolik, J. C. Gallucci and A. Wojcicki, J. Am. Chem. Soc., 1993, 115, 9986; (b) V. Plantevin and A. Wojcicki, J. Organomet. Chem., 2004, 689, 2000.

34 A. M. Geyer, R. L. Gdula, E. S. Wiedner and M. J. Johnson, J. Am. Chem. Soc., 2007, 129, 3800.

35 B. W. H. Saes, D. G. A. Verhoeven, M. Lutz, R. J. M. Klein Gebbink and M.-E. Moret, Organometallics, 2015, 34, 2710 . 